\title{
Dopaminergic Influence Over Hippocampal Synaptic Plasticity and Function
}

\author{
John I Broussard, Daniel Jenson, and John A Dani* \\ Center on Addiction, Learning, Memory, Department of Neuroscience, Baylor College of Medicine, Houston, TX 77030, USA
}

Keywords: Dopamine; Hippocampus; Mesolimbic; Ventral tegmental area; Nucleus accumbens; Long-term potentiation; Memory

The hippocampal formation is an important center for spatial and episodic memories. In the most simplified terms, multi-sensory information from the entorhinal cortex enters the dentate gyrus and begins a trisynaptic loop through the CA 3 subfield and then to the CA1 subfield of the hippocampus. While the neuronal connections involved are primarily excitatory and inhibitory, there is neuromodulatory innervation of the hippocampus arising from cholinergic and noradrenergic centers. The medial septum provides cholinergic and GABAergic input to the hippocampus, and the consensus is that this regulates theta oscillations that contribute to mechanisms of both plasticity and memory [1]. It has also been demonstrated that the locus coerulus provides a second source of neuromodulation via noradrenergic afferents to the hippocampus [2]. The most common anatomical marker for both norepinephrine and dopamine (DA) synthesis is Tyrosine Hydroxylase (TH), which does not distinguish between the two neurotransmitters. Thus, there is not a clear consensus regarding the extent of direct dopaminergic (DA) innervation from the Ventral Tegmental Area (VTA). Several lines of evidence suggest that DA neurotransmission influences hippocampal plasticity $[3,4]$ and function [5], but some recent work questions whether these effects arise from direct dopaminergic afferents or from co-release of DA from noradrenergic fibers within the hippocampus [6]. Here we will discuss the discrepancy arising from several different approaches, and how two viable hypotheses of dopaminergic influence over hippocampal function have arisen.

There have been a number of studies supporting the functional role of dopaminergic D1/D5 receptors that are expressed in the hippocampus. Immunohistochemistry has revealed that these receptors are expressed in the dentate gyrus, CA1, and CA3 of the hippocampal formation [7], and on excitatory neurons [8]. DA enhances the excitability of hippocampal neurons by decreasing the calcium activated potassium conductance, thereby reducing the after hyper polarization of the action potential [9]. Further, inhibition of D1-type receptors prevented nicotine-induced in vivo synaptic potentiation measured in the dentate gyrus [10]. In addition, the amplitude of the dendritic action potential is enhanced by D1/D5 neurotransmission [11]. Recordings from hippocampal brain slices showed that D1/ D5 receptor neurotransmission supports induction of late phase long term potentiation in CA1 synapses, an effect that is dependent upon protein synthesis [12]. Furthermore, it was shown that D1/D5 neurotransmission is important for the consolidation or persistence of long term memories $[5,13,14]$.

Despite these varied forms of anatomical and functional evidence supporting the importance of D1/D5 receptor signaling in the hippocampus, the anatomical projections from known dopaminergic centers are relatively sparse. In 1978, Moore and Bloom [15] published a review of Substantia Nigra Compacta (SNc) and Ventral Tegmental Area (VTA) projections, and they make no mention of the hippocampus. However, one year later they presented strong evidence of noradrenergic projections to the hippocampus [2]. Since then, two groups have used either retrograde or anterograde labeling to establish projections from the VTA to the hippocampus [16-18]. Anterograde tracing from the VTA demonstrated projections to the stratum oriens of the dorsal CA1, broad innervations of ventral CA1, and sparser projections to the CA3 and dentate gyrus. However, only a minority of the VTA neurons that project to the hippocampus are dopaminergic, with one estimate of TH-co-labeled projections being as low as 6\% [18], and between $10-18 \%$ in others $[16,17]$. Retrograde tracing combined with immunofluorescence from the CA1 indicated that dopaminergic VTA projections are mainly from the peribrachial pigmented nuclei of the VTA [16]. Modern molecular techniques may revise or confirm these early estimates of VTA dopaminergic innervation of the hippocampus.

One factor that complicates the interpretation of dopaminergic innervation of the hippocampus is that DA is the precursor to norepinephrine, and the rate-limiting enzyme for the synthesis of both catecholamines is Tyrosine Hydroxylase (TH). Early approaches used injections of 6-hydroxydopamine (6-OHDA) specifically into either the locus coerulus or VTA to lesion TH-containing neurons. Using this chemical lesion, it was shown that hippocampal DA levels were markedly reduced following injections into the VTA but not when the injections were into the substantia nigra [19] or the locus coerulus [20].

The discrepancy between the importance of functional D1/D5 neurotransmission in the hippocampus and the evidence for sparse direct VTA projections to the hippocampus lead to two plausible hypotheses. The first is that sparse dopaminergic neurons projecting to the hippocampus may have fewer DA transporters, and other catecholamine transporters have a role in dopamine clearance [21]. Therefore, the low levels of released DA are not cleared rapidly and, thus, remain in the synapse longer. The resulting "volume transmission" of DA is then able to influence synaptic events on a longer time scale [22].

The second hypothesis is that locus coerulus noradrenergic projections may also release dopamine $[23,24]$. A recent study provides evidence in support of this second hypothesis, demonstrating that amphetamine produces dopamine-dependent changes in hippocampal synaptic plasticity, and in this case the DA is derived from locus coerulus noradrenergic terminals [6]. Synaptic plasticity is a proxy or indicator for changes in neural function, and changes in hippocampal plasticity are thought to underlie changes in learning and memory. The CA1 subfield of the hippocampus is the final field of the trisynaptic hippocampal loop, and it is crucial for forming a cognitive spatial

*Corresponding author: John A Dani, CALM, Department of Neuroscience, Baylor College of Medicine, Houston, TX 77030-3498, USA, Tel: 713-798-3710; Fax: 713-798-3946; E-mail: jdani@bcm.edu

Received December 26, 2012; Accepted December 28, 2012; Published December 31, 2012

Citation: Broussard JI, Jenson D, Dani JA (2012) Dopaminergic Influence Over Hippocampal Synaptic Plasticity and Function. Clin Exp Pharmacol 2:e108. doi:10.4172/2161-1459.1000e108

Copyright: (c) 2012 Broussard Jl, et al. This is an open-access article distributed under the terms of the Creative Commons Attribution License, which permits unrestricted use, distribution, and reproduction in any medium, provided the original author and source are credited. 
and temporal map $[25,26]$. CA1 synaptic plasticity can be measured by stimulating Shaffer collateral axons from the CA3 subfield and measuring the synaptic responses where the Shaffer collaterals form synaptic connections with the dendrites of pyramidal neurons in the CA1 subfield. In support of the hypothesis that noradrenergic/ norepinephrine (NE) terminals also release DA, Smith and Greene [6] recorded from the stratum radiatum of hippocampal slices and stimulated the Shaffer collaterals, and they demonstrated that amphetamine modulates the slope of the field Excitatory Post-Synaptic Potential (fEPSP) via local D1/D5 neurotransmission, and not via $\beta$-adrenergic receptors. Then, they injected adeno-associated virus specifically designed to silence $\mathrm{TH}$, into either the locus coerulus or VTA. When they silenced TH in the LC, but not the VTA, the authors blocked amphetamine-enhanced plasticity of CA1 neurons. Based on this evidence, Smith and Greene suggested that amphetamine blocks the vesicular packing of DA in terminals, and the resultant accumulation of presynaptic DA results in reverse transport through NE transporters. While their techniques and experiments are alluring, their approach suggests that locus coerulus neurons mainly release DA under the influence of amphetamine, which does not explain why D1/D5 receptors seem to be functionally influential even in absence of amphetamine $[5,7,13,27]$.

A corollary to this hypothesis that DA is released from adrenergic terminals is that specific locus coerulus projections to the hippocampus may lack dopamine $\beta$-hydroxylase, which catalyzes the conversion of DA to norepinephrine. Thus, what are thought to be norepinephrine terminals are actually functioning as DA terminals [28]. A recent paper highlighted the type of techniques required to investigate this issue. Transgenic mice were generated that specifically expressed a trans-synaptic tracer, Wheat Germ Agglutinin (WGA) in locus coerulus neurons, and this expression was controlled by the dopamine $\beta$-hydroxylase gene promoter [29]. In these mice the trans-synaptic tracer was transferred across the synapses from all locus coerulus neurons containing dopamine $\beta$-hydroxylase. Interestingly, dopamine $\beta$-hydroxylase positive projections could be found predominantly in the CA3 with some projections to the dentate gyrus, whereas little or no such projections were found in the CA1 subfield. It is unclear based on this study alone whether norepinephrine fibers project to CA1 or not, or whether these projections are dopaminergic and thus do not contain dopamine $\beta$-hydroxylase. Some previous studies have indicated that a larger proportion of norepinephrine terminals are located in the CA3 and dentate gyrus ([30,31], but see [32]). Yet another study shows dense expression of dopamine $\beta$-hydroxylase in the molecular layer of the CA1 [33], which overlaps with $\mathrm{TH}$ positive expression.

In summary, there are dopaminergic mechanisms at work in the hippocampus, but the density of direct DA innervations is still in question. Future anatomical work that applies state-of-the-art molecular technology will be able to differentiate between the two current hypotheses, and that work will likely extend presently held conceptions. It is likely that sparse, diffuse dopaminergic projections from the VTA innervate the hippocampus. Because the density of DA transporters is low, even a small amount of innervation can produce a DA signal that spreads from the release sites and influences synaptic events. In addition, under a least some circumstances norepinephrine terminals produce a DA signal dependent of the activity of fibers from the locus coerulus.

\section{Acknowledgments}

The authors are supported by grants from the National Institutes of Health, NIDA DA09411 and NINDS NS21229, and by the Cancer Prevention and Research Institute of Texas, and by the Diana Helis Henry Medical Research Foundation through its direct engagement in the continuous active conduct of medical research in conjunction with Baylor College of Medicine and the project, Genomic, Neural, Preclinical Analysis for Smoking Cessation, and the Cancer Program.

\section{References}

1. Hasselmo ME, Hay J, llyn M, Gorchetchnikov A (2002) Neuromodulation, theta rhythm and rat spatial navigation. Neural Netw 15: 689-707.

2. Moore RY, Bloom FE (1979) Central catecholamine neuron systems: anatomy and physiology of the norepinephrine and epinephrine systems. Annu Rev Neurosci 2: 113-168

3. Kulla A, Manahan-Vaughan D (2000) Depotentiation in the dentate gyrus of freely moving rats is modulated by D1/D5 dopamine receptors. Cereb Cortex 10: 614-620.

4. Sajikumar S, Frey JU (2004) Late-associativity, synaptic tagging, and the role of dopamine during LTP and LTD. Neurobiol Learn Mem 82: 12-25.

5. Rossato JI, Bevilaqua LR, Izquierdo I, Medina JH, Cammarota M (2009) Dopamine controls persistence of long-term memory storage. Science 325 : 1017-1020.

6. Smith CC, Greene RW (2012) CNS dopamine transmission mediated by noradrenergic innervation. J Neurosci 32: 6072-6080.

7. Mu Y, Zhao C, Gage FH (2011) Dopaminergic modulation of cortical inputs during maturation of adult-born dentate granule cells. J Neurosci 31: 4113 4123 .

8. Khan ZU, Gutierrez A, Martin R, Penafiel A, Rivera A, et al. (2000) Dopamine D5 receptors of rat and human brain. Neuroscience 100: 689-699.

9. Malenka RC, Nicoll RA (1986) Dopamine decreases the calcium-activated afterhyperpolarization in hippocampal CA1 pyramidal cells. Brain Res 379 210-215.

10. Tang J, Dani JA (2009) Dopamine enables in vivo synaptic plasticity associated with the addictive drug nicotine. Neuron 63: 673-682.

11. Hoffman DA, Johnston D (1999) Neuromodulation of dendritic action potentials. J Neurophysiol 81: 408-411.

12. Huang YY, Kandel ER (1995) D1/D5 receptor agonists induce a protein synthesis-dependent late potentiation in the CA1 region of the hippocampus. Proc Natl Acad Sci U S A 92: 2446-2450.

13. Bethus I, Tse D, Morris RG (2010) Dopamine and memory: modulation of the persistence of memory for novel hippocampal NMDA receptor-dependent paired associates. J Neurosci 30: 1610-1618.

14. Lisman JE, Grace AA (2005) The hippocampal-VTA loop: controlling the entry of information into long-term memory. Neuron 46: 703-713.

15. Moore RY, Bloom FE (1978) Central catecholamine neuron systems: anatomy and physiology of the dopamine systems. Annu Rev Neurosci 1: 129-169.

16. Gasbarri A, Verney C, Innocenzi R, Campana E, Pacitti C (1994) Mesolimbic dopaminergic neurons innervating the hippocampal formation in the rat: a combined retrograde tracing and immunohistochemical study. Brain Res 668 71-79.

17. Gasbarri A, Sulli A, Packard MG (1997) The dopaminergic mesencephalic projections to the hippocampal formation in the rat. Prog Neuropsychopharmaco Biol Psychiatry 21: 1-22.

18. Swanson LW (1982) The projections of the ventral tegmental area and adjacent regions: a combined fluorescent retrograde tracer and immunofluorescence study in the rat. Brain Res Bull 9: 321-353.

19. Scatton B, Simon H, Le Moal M, Bischoff S (1980) Origin of dopaminergic innervation of the rat hippocampal formation. Neurosci Lett 18: 125-131.

20. Bischoff S, Scatton B, Korf J (1979) Biochemical evidence for a transmitter role of dopamine in the rat hippocampus. Brain Res 165: 161-165.

21. Borgkvist A, Malmlof T, Feltmann K, Lindskog M, Schilstrom B (2012) Dopamine in the hippocampus is cleared by the norepinephrine transporter. Int J Neuropsychopharmacol 15: 531-540.

22. Agnati LF, Zoli M, Stromberg I, Fuxe K (1995) Intercellular communication in the brain: wiring versus volume transmission. Neuroscience 69: 711-726.

23. Devoto P, Flore G (2006) On the origin of cortical dopamine: is it a co-transmitter in noradrenergic neurons? Curr Neuropharmacol 4: 115-125. 
Citation: Broussard JI, Jenson D, Dani JA (2012) Dopaminergic Influence Over Hippocampal Synaptic Plasticity and Function. Clin Exp Pharmacol 2:e108. doi:10.4172/2161-1459.1000e108

24. Devoto P, Flore G, Pani L, Gessa GL (2001) Evidence for co-release of noradrenaline and dopamine from noradrenergic neurons in the cerebral cortex. Mol Psychiatry 6: 657-664.

25. O'Keefe J, Nadel L (1978) The hippocampus as a cognitive map. Oxford, Oxford University Press, UK.

26. Ferbinteanu J, Kennedy PJ, Shapiro ML (2006) Episodic memory--from brain to mind. Hippocampus 16: 691-703.

27. Lisman J, Grace AA, Duzel E (2011) A neoHebbian framework for episodic memory; role of dopamine-dependent late LTP. Trends Neurosci 34: 536-547.

28. Swanson LW, Hartman BK (1975) The central adrenergic system. An immunofluorescence study of the location of cell bodies and their efferent connections in the rat utilizing dopamine-beta-hydroxylase as a marker. $J$ Comp Neurol 163: 467-505.

29. Walling SG, Brown RA, Miyasaka N, Yoshihara Y, Harley CW (2012) Selective wheat germ agglutinin (WGA) uptake in the hippocampus from the locus coeruleus of dopamine- $\beta$-hydroxylase-WGA transgenic mice. Front Behav Neurosci 6: 23

30. Milner TA, Bacon CE (1989) Ultrastructural localization of tyrosine hydroxylaselike immunoreactivity in the rat hippocampal formation. J Comp Neurol 281 479-495.

31. Koda LY, Schulman JA, Bloom FE (1978) Ultrastructural identification of noradrenergic terminals in rat hippocampus: unilateral destruction of the locus coeruleus with 6-hydroxydopamine. Brain Res 145: 190-195.

32. Pasquier DA, Reinoso-Suarez F (1978) The topographic organization of hypothalamic and brain stem projections to the hippocampus. Brain Res Bul 3: 373-389.

33. Moudy AM, Kunkel DD, Schwartzkroin PA (1993) Development of dopaminebeta-hydroxylase-positive fiber innervation of the rat hippocampus. Synapse 15: 307-318. 